\title{
WEIGHTED HARDY-TYPE INEQUALITIES ON THE CONE OF QUASI-CONCAVE FUNCTIONS
}

\author{
L.-E. Persson, O. V. Popova and V. D. Stepanov
}

Abstract. The paper is devoted to the study of weighted Hardy-type inequalities on the cone of quasi-concave functions, which is equivalent to the study of the boundedness of the Hardy operator between the Lorentz $\Gamma$-spaces. For described inequalities we obtain necessary and sufficient conditions to hold for parameters $q \geqslant 1, p>0$ and sufficient conditions for the rest of the range of parameters.

Mathematics subject classification (2010): 39B62, 45P05.

Keywords and phrases: Hardy operator, Hardy-type inequality, weight, measure, Lorentz space, concave function, quasi-concave function.

\section{REFERENCES}

[1] M. ARiÑo, B. MucKenhoupt, Maximal functions on classical Lorentz spaces and Hardy's inequality with weights for non-increasing functions, Trans. Amer. Math. Soc. 320 (1990), 727-735.

[2] I. U. Asekritova, N. Ya. Krugljak, L. Maligranda, L.-E. Persson, Distribution and rearrangement estimates of the maximal function and interpolation, Studia Math. 124 (1997), 107-132.

[3] G. BennetT, K.-G. Grosse-ERdmann, Weighted Hardy inequalities for decreasing sequences and functions, Math. Ann. 334 (2006), 489-531.

[4] C. Bennett, R. Sharpley, Interpolation of operators, Academic Press, Boston, 1988.

[5] J. Bergh, J. LÖFström, Interpolation Spaces. An introduction, Springer, Berlin, 1976.

[6] M. J. Carro, L. Pick, J. Soria, V. D. Stepanov, On embeddings between classical Lorentz spaces, Math. Inequal. Appl. 4 (2001), 397-428.

[7] M. J. Carro, A. Gogatishvili, J. Martin, L. Pick, Weighted inequalities involving two Hardy operators with applications to embeddings of function spaces, J. Operator Theory $\mathbf{5 9}$ (2008), 309-332.

[8] A. Gogatishvili, L. Pick, Discretization and anti-discretization of rearrangement-invariant norms, Publ. Mat. 47 (2003), 311-358.

[9] A. Gogatishvili, V. D. Stepanov, Reduction theorems for weighted integral inequalities on the cone of monotone functions, Russian Math. Surveys 68 (2013), 597-664.

[10] A. Gogatishvili, V. D. Stepanov, Reduction theorems for operators on the cones of monotone functions, J. Math. Anal. Appl. 405 (2013), 156-172.

[11] A. Gogatishvili, V. D. Stepanov, Operators on the cones of monotone functions, Doklady Math. 86 (2012), 562-565.

[12] M. L. Goldman, Sharp estimates for the norms of Hardy-type operators on cones of quasimonotone functions, Proc. Steklov Inst. Math. 232 (2001), 109-137.

[13] M. L. Goldman, Order-sharp estimates for Hardy-type operators on cones of quasimonotone functions, Eurasian Math. J. 2, 3 (2011), 143-146.

[14] M. L. Goldman, H. P. Heinig, V. D. Stepanov, On the principle of duality in Lorentz spaces, Canad. J. Math. 48 (1996), 959-979.

[15] M. L. Goldman, M. V. Sorokina, Three-weighted Hardy-type inequalities on the cone of quasimonotone functions, Dokl. Math. 71 (2005), 209-213.

[16] H. Heinig, L. MaligRAndA, Weighted inequalities for monotone and concave functions, Studia Math. 116 (1995), 133-165. 
[17] M. Johansson, V. D. Stepanov, E. P. Ushakova, Hardy inequality with three measures on monotone functions, Math. Inequal. Appl. 11 (2008), 393-413.

[18] L. V. Kantorovich, G. P. Akilov, Functional Analysis, Pergamon Press, Oxford, 1982.

[19] A. Kufner, L.-E. Persson, Weighted inequalities of Hardy type, World Scientific, New Jersey, 2003.

[20] A. Kufner, L. Maligranda And L.-E. Persson, The Hardy inequality. About its history and some related results, Vydavatelsky Servis, Pilsen, 2007.

[21] G. G. LoREnTZ, On the theory of spaces $\Lambda$, Pacific J. Math. 1 (1951), 411-429.

[22] L. Maligranda, Weighted inequalities for quasi-monotone functions, J. London Math. Soc. 57 (1998), 363-370.

[23] R. Oinarov, Two-sided estimates for the norm of some classes of integral operators, Proc. Steklov Inst. Math. 204 (1994), 205-214.

[24] B. OpIC, A. Kufner, Hardy-type Inequalities, Pitman Research Notes in Math., Series 219, Longman Sci \& Tech., Harlow, 1990.

[25] L.-E. Persson, N. SAMKO, P. WALL, Quasi-monotone weight functions and their characteristics and applications, Math. Inequal. Appl. 12 (2012), 685-705.

[26] L.-E. Persson, V. D. Stepanov, E. P. Ushakova, Equivalence of Hardy-type inequalities with general measures on the cones of non-negative respective non-increasing functions, Proc. Amer. Math. Soc. 134 (2006), 2363-2372.

[27] D. V. Prokhorov, Hardy's inequality with three measures, Proc. Steklov Inst. Math. 255 (2006), 221-233.

[28] D. V. Prokhorov, Inequalities of Hardy type for a class of integral operators with measures, Anal. Math. 33 (2007), 199-225.

[29] E. SAWYER, Boundedness of classical operators on classical Lorentz spaces, Studia Math. 96 (1990), $145-158$.

[30] G. Sinnamon, Embeddings of concave functions and duals of Lorentz spaces, Publ. Mat. 46 (2002), 489-515.

[31] G. Sinnamon, V. D. Stepanov, The weighted Hardy inequality: new proofs and the case $p=1$, J. London Math. Soc. 54 (1996), 89-101.

[32] V. D. Stepanov, Integral operators on the cone of monotone functions, J. London Math. Soc. 48 (1993), 465-487.

[33] V. D. StePanov, The weighted Hardy's inequality for non-increasing functions, Trans. Amer. Math. Soc. 338 (1993), 173-186. 